\title{
Publisher Correction: Alpha-fetoprotein inhibits autophagy to promote malignant behaviour in hepatocellular carcinoma cells by activating PI3K/AKT/mTOR signalling
}

Shanshan Wang ${ }^{1,2}$, Mingyue Zhư ${ }^{3}$, Qiaoyun Wang ${ }^{3}$, Yuli Hou', Lei Li ${ }^{5}$, Honglei Weng ${ }^{6}$, Yan Zhao ${ }^{4}$, Dexi Chen ${ }^{1,2}$, Junli Guo ${ }^{3}$, Huiguo Ding ${ }^{5}$ and Mengsen Li ${ }^{3}$

\section{Correction to: Cell Death and Disease;} https://doi.org/10.1038/s41419-018-1036-5; published online 9 October 2018
The article published with errors in the authors' information. The correct ordering and designations for corresponding / first authors are shown here.

Published online: 01 March 2019

\footnotetext{
Correspondence: Huiguo Ding (dinghuiguo@medmail.com.cn) or

Mengsen Li (mengsenli@163.com)

'Beijing Institute of Hepatology, Beijing Youan Hospital, Capital Medical University, Beijing, China

${ }^{2}$ Beijing Precision Medicine and Transformation Engineering Technology Research Center of Hepatitis and Liver Cancer, Beijing, China

${ }^{3}$ Hainan Provincial Key Laboratory of Carcinogenesis and Intervention, Hainan Medical College, Haikou, China

${ }^{4}$ Clinical Laboratory Center, Beijing Youan Hospital, Capital Medical University, Beijing, China

${ }^{5}$ Department of Gastrointestinal and Hepatology, Beijing Youan Hospital,

Capital Medical University, Beijing, China

${ }^{6}$ Molecular Hepatology, University of Heidelberg, University Medical Center

Mannheim, 68167 Mannheim, Germany

These authors contributed equally to this work: Shanshan Wang, Mingyue Zhu,

Qiaoyun Wang
}

(c) (i) Open Access This article is licensed under a Creative Commons Attribution 4.0 International License, which permits use, sharing, adaptation, distribution and reproduction in any medium or format, as long as you give appropriate credit to the original author(s) and the source, provide a link to the Creative Commons license, and indicate if changes were made. The images or other third party material in this article are included in the article's Creative Commons license, unless indicated otherwise in a credit line to the material. If material is not included in the article's Creative Commons license and your intended use is not permitted by statutory regulation or exceeds the permitted use, you will need to obtain permission directly from the copyright holder. To view a copy of this license, visit http://creativecommons.org/licenses/by/4.0/. 